\title{
WELCOME BY THE HUNGARIAN ACADEMY OF SCIENCES
}

\author{
L. DeTrE \\ (Konkoly Observatory, Budapest, Hungary)
}

\section{Dear Colleagues, Ladies and Gentlemen:}

On behalf of the Hungarian Academy of Sciences and of the Hungarian National Committee of the IAU I extend a most cordial welcome to you.

Symposium 35 is the first IAU meeting which is held in Hungary. I express sincere thanks to Commissions 10 and 12 for having given our Academy the honour to house it.

I thank all of you for having come to Budapest to attend the symposium. We never had before in Hungary a gathering of so many distinguished astronomers and geophysicists.

Special thanks are due to Professor Kiepenheuer for his continuous help to the Local Organizing Committee with his great experience and valuable advices. In January he made an extra travel to Budapest to talk over with us every detail of the organization, and even now nothing escapes his attention.

In recent years by the help of our Academy we made efforts to modernize our astronomical observatories, and as a first step we have built a new mountain-station $120 \mathrm{~km}$ northeast of Budapest. This was especially necessary because the Konkoly Observatory at its old place on the Szabadsághegy near Budapest suffered very much from the smoke and illumination of the city. Till now we have installed a $90 / 60-\mathrm{cm}$ Schmidt telescope with objective prisms and a $50-\mathrm{cm}$ Cassegrain telescope with a two-channel polarimeter. I hope to obtain later a telescope with an aperture of $1 \frac{1}{2} \mathrm{~m}$. The next step will be the modernization of the Solar Physics Observatory at Debrecen.

In the last issue of the Irish Astronomical Journal one can read a poem which is an ingenious summary of the problems of solar physics, having the title 'A Solar Physicist's Lament'. I wish you to get rid of some laments at this symposium. But naturally, with the last words of the poem

It looks as if many a sunny day

Will pass along on its way

Before we solve it all.

I very much hope you will have a pleasant stay in Hungary and an exciting symposium.

Now, I declare IAU Symposium 35 on the Structure and Development of Solar Active Regions open and I call on Dr. Leighton to take the chair. 